\title{
The Allee Effect: Its History and Future Importance
}

\author{
William Z. Lidicker, Jr. \\ Museum of Vertebrate Zoology and Department of Integrative Biology, University of California, Berkeley, CA 94720- \\ 3160, USA
}

\begin{abstract}
The role of mutually beneficial interactions (++, cooperation) is a rapidly growing research field in population dynamics, microevolution, and conservation biology. Such positive influences cause destabilizing pressures in population dynamics (anti-regulating factors), and can generate Allee effects. Not only can large demes benefit from such cooperation, but the loss of cooperation in small demes can produce a minimum threshold density. Interest in these phenomena grew rapidly to the middle of the 20th century, followed by about four decades in which interest waned. In the last 20 years attention to Allee effects has burgeoned once again. This renewal has produced new perspectives, including a more realistic framework for the way populations and communities are organized. A core concept for Allee effects emerges from the historical record and current views on population dynamics: Allee effects are demographic consequences of the collective actions of anti-regulating influences. Recent developments, including proposals for much new terminology, are reviewed and found to be helpful in building mechanistic understanding of the core concept. Support for the growing relevance of Allee effects to conservation biology as well as population and community dynamics is emphasized. Some new avenues for future research directions include improving our abilities to predict life history and environmental features that favor strong anti-regulation and hence Allee effects, the role of mutually positive interspecific relations in community function, and possible role of anti-regulation in restoration ecology.
\end{abstract}

Keywords: Cooperation, facilitation, anti-regulation, minimum threshold density, population dynamics, Darwinian fitness, extinction, demography, conservation, density dependence.

\section{INTRODUCTION}

The Allee effect has achieved a deserved reputation as a significant concept in ecology and conservation biology. Along with this recognition, there has developed an array of elaborations, clarifications, and sometimes seemingly unnecessary complexities, along with a rapidly expanding body of supporting empirical data. At this stage in its history, it seems important to pause long enough to look back in some detail into where the idea came from, to consider where we are at the present, and to risk a look into the immediate future. Therefore, in this essay I will attempt to a) reconstruct the main threads of the history of the Allee effect as a concept, b) ask whether or not there is a core conceptual basis for the idea upon which we can build new understanding, and c) look forward to new developments.

To set the historical stage, it is interesting to point out that the Allee effect shares a history not unlike that of many other important ideas in science that are launched in an unsupportive intellectual context, and hence are slow to be recognized for their inherent value. The experiences of Galileo (Galilei) in astronomy and Gregor Mendel in genetics are two obvious earlier examples. Sometimes the new insight will enjoy a flash of recognition before being buried in the conventional wisdom of the times. The Allee

*Address correspondence to this author at the Museum of Vertebrate Zoology and Department of Integrative Biology, University of California, Berkeley, CA 94720-3160, USA; Tel: 510-643-7713; Fax: 510-643- 8238; E-mail: wlidicker@berkeley.edu

Handling editor: Pablo Munguia effect has experienced such an odyssey. Conceptually it has a long history going back to classical times, leading to several decades in the early $20^{\text {th }}$ century when it was formalized and popularized by W.C. Allee and colleagues before almost disappearing into obscurity.

In recent decades these ideas have re-emerged as popular and important concepts in ecology and conservation biology. The recent book by Courchamp et al. (2008) is an example of a well written and informative review of the current situation. Other important recent contributions include (Berec, et al. 2007, Courchamp et al. 1999a, 1999b, Dennis 2002, De Roos et al., 2003, Kramer et al. 2009, Morris 2002, Stephens and Sutherland 1999, Stephens et al. 1999). These contributions and many others cited by them and some mentioned in this review document the now massive and rapidly growing empirical evidence for the widespread occurrence of Allee effects. In this paper, I will only review the evidence in general terms. This trend, however, should be viewed as a favorable signal of the growing interest in the phenomenon and recognition of its importance in modern population dynamics, community ecology, and conservation biology.

\section{ALLEE'S ANTECEDENTS}

The Allee effect concept or principle is based on the existence of mutually beneficial (cooperative) interactions among conspecific organisms. While the existence of such forces cannot be denied, it has not always been accepted by biologists that cooperation is a ubiquitous and important organizing influence in the living world. An early expression 
of the general importance of cooperation has been attributed to the Greek philosopher Empedocles who in the $5^{\text {th }}$ century $\mathrm{BC}$ proffered the view that cooperation and struggle (love and hate) were two balancing forces which interacted with the four basic elements (fire, earth, air, water) to form organisms and alter them over time to make them more perfect (cited in Allee 1951, p. 7). The intellectual history that explores the extent and meaning of organisms helping each other is complex, intertwined with many philosophical and social issues, and is clearly beyond the scope of this paper. Suffice it to say that ecology is undergoing a revolution of increasing recognition of the importance and ubiquity of cooperative (mutually beneficial) interactions among organisms, both within and between species, both directly and indirectly, and both actively and passively (Boucher 1985, Keddy 1990, Dugatkin 1997, Kozo-Polyansky et al. 2010, White \& Torres 2009). This development is an essential substrate for the growing awareness and recognition of Allee effects.

Our historical vignette resumes with Charles Darwin who was very much aware of the importance of positive interactions. He pondered the evolution of sociality in insects, and worried that his notions of "struggle" and intense competition for survival would obscure the importance of cooperation. He explained, for example, that "Those communities which included the greatest number of the most sympathetic members would flourish best, and rear the greatest number of offspring" (quoted in Kropotkin 1902, p. 2), and "I use this term [struggle for existence] in a large and metaphorical sense including dependence of one being on another ...." (quoted in Allee 1951, p. 9). An early modern publication to express this view in the context of biology was that of Espinas (1877) who wrote about animal societies. A very influential, if controversial, figure was Petr Alekseevich Kropotkin (1885-1921) who in 1902 published his famous book called "Mutual Aid, a factor in evolution" which was reprinted in 1955 and again in 1972. He was an avid Darwinist whose views on the potential survival value of cooperation were gained by much experience in Siberia, and reflected the recognition that ecological systems were composed of a balance of positive and negative interactions. Such views were common among intellectuals in Russia and Eastern Europe at the time (see also Gould 1988). Another contribution in this same vein was the influential book by W. M. Wheeler (1928) on social insects. However, by the mid$20^{\text {th }}$ century, this balanced view was largely replaced by a strong emphasis on the importance of competition in ecology and in evolution.

There were of course many others who contributed to these developments, but for our limited purposes here, these key players are illustrative, and set the stage for the ensuing debates about the relative role of positive versus negative forces in population dynamics, in structuring natural communities, and in the evolutionary process.

\section{THE ALLEE EFFECT ACCORDING TO WARDER CLYDE ALLEE}

W. C. Allee died in 1955 after a long career as an ecologist at the University of Chicago. He was aware that the most common dispersion pattern among organisms was contagious or clumped, and that random or even-spacing were rarer. Moreover, he was impressed, both from his own observations and from the literature, with the importance of mutually positive interactions among individuals of the same species, that is, cooperation or facilitation among members of a population. He went on to perform many laboratory experiments that demonstrated how increasing numbers in a population often allowed the group to modify their environment, fend off predation, resist toxic influences, reproduce faster, or in other ways improve their success individually and collectively. There were in these cases positive relationships between population numbers and the ability of a population to persist and/or reproduce successfully (Allee 1931, 1932, 1938, 1951). His experiments were mostly on invertebrates, but he also used bacteria, goldfish, and even mice. Variables measured were diverse, including metabolic rate, speed of learning, survival of marine organisms in fresh water, resistance to toxins, population growth rate in the case of bacteria, life span of sperm, and rate of embryological development. A typical experiment can be illustrated by one utilizing goldfish subjected to lethal concentrations of colloidal silver (Allee \& Bowen 1932). Seventy fish were placed in 7 groups of 10 each, and 70 more were isolated as individuals. The average time to death in the grouped fish was 507 minutes and that of the singles was $182 \mathrm{~min}$. ( $\mathrm{p}<$ $0.001)$.

This rapidly accumulating evidence for positive effects associated with increasing numbers during this early period does not of course lead to the conclusion that populations exhibiting these behaviors grow forever. Demographic theory, as well as the finite nature of the Earth, requires that various regulating factors (negative influences at high densities) will eventually overwhelm growth promoting forces and stop growth or cause it to become negative. Nevertheless, cooperative forces could allow a population to generate a higher level of average well-being, produce more successful emigrants or colonists, achieve a higher equilibrium density, or perhaps reach it faster than would be possible without this cooperation. The resulting demographic pathway will depend on the mix of increasingly positive and increasingly negative influences as numbers increase, and on how this mix changes over time. In his 1931 book, Allee (1931) included three chapters on the negative effects of crowding and eight chapters on the beneficial effects. Nothing was said about potential negative effects at low numbers.

Gradually Allee realized that if these cooperative effects were indeed significant in high density populations, a corollary of this is that as populations declined to low levels, there could be insufficient numbers to achieve the cooperative benefits, and small populations might suffer from not only what caused the decline in numbers in the first place but additionally from the loss of benefits achieved through cooperation (Allee, et al. 1949, Allee 1951). Thus, while cooperative behavior could enhance population performance, it carried the risk that at low densities its loss could lead to an increased chance of extinction. Interestingly, Darwin set the stage for this insight about the demographic risks of small population size when he wrote "in many cases a large stock of individuals of the same species, relatively to the number of its enemies, is absolutely necessary for its preservation" (Darwin 1872, p. 86). As early as 1932, Allee 
pointed out that "minimum populations may not be most favorable for rapid growth" (Allee 1932, p. 128-129) as is assumed in logistic models of population growth. In his famous ecology text (Allee et al. 1949), this disadvantage suffered by small populations was called "undercrowding" or the result of "inverse density dependence".

An important contributor to these insights at this early stage was Frank Fraser Darling. He was an eccentric Scotsman who made many contributions in ecology and social behavior, wrote at least a dozen books (latest in 1972), and pioneered the radical idea that human ecology could be a useful subset of ecology. For our purposes here, his classic research on marine bird colonies is most relevant and was very influential (Darling 1938). His research emphasized the low population numbers end of the Allee effect spectrum. He observed in a number of species (for example, the Razorbilled Auk, Alca torda) that when the size of a breeding colony dropped below a certain threshold number, breeding failed and the colony became extinct. He attributed this failure to a lack of reproduction caused by insufficient social stimuli from courtship behavior. He also invented the concept of predator swamping, although the phenomenon was reported earlier by Howard (1920). He observed, for example in the Herring Gull (Larus argentatus), that the synchrony of breeding in a colony depended on the size of the colony. The larger the colony, the more synchronous was the hatching of chicks. Greater synchrony led to a reduced loss of eggs and chicks to predators because the predators could harvest only a small percentage of the available food before the chicks became too large to be vulnerable. When synchrony was weak, predators could kill a greater percentage of the total production of young, and in very small colonies breeding success was zero. The evident need for a minimum colony size for successful breeding means that it is difficult for species exhibiting this behavior to start new colonies. Darling's research was cited by Allee, and undoubtedly encouraged his appreciation of the low density consequences of his growing data base on the positive demographic effects of mutually beneficial interactions in large groups. For many years, the low density consequences attributable to losses in cooperative behavior were known as the "Darling effect" (Chabrzyk \& Coulson 1976, Wilson 1975, Wynne-Edwards 1962), and the high density positive effects as the "Allee effect." It is therefore ironic that in current literature, the Allee effect is often restricted to the low density component (Angulo et al. 2007, Courchamp et al. 1999a, Fowler \& Baker 1991, Gregory \& Courchamp 2010, Kramer \& Drake 2010, Myers et al. 1995, Stephens \& Sutherland 1999, Stephens, et al. 1999).

Finally, it is interesting to consider if Allee developed an explicit definition of what we now call the Allee effect. It is clear from the above outline of history that his ideas evolved as data accumulated. But, as early as 1931 when he was thinking mainly about positive interactions in large, high density populations, he was writing about stimulation of population growth, increased reproductive rates, and improved survival resulting from protection of individuals, resistance to toxins, faster individual development, etc. Thus, it is apparent that he had no difficulties in incorporating the benefits to individuals resulting from mutually positive interactions into population level processes such as population growth, reproductive, and survival rates. By 1932, he wrote about the negative effects of low numbers on population growth rates, and in 1949 he was pointing out how these low number effects violated the assumptions of the logistic growth equation, a population-level concept. Perhaps the best illustration of the concept as he eventually understood it is in Odum \& Allee (1954). Fig. 2 in their paper illustrates the same concept as expressed here in my Fig. (1) with its two equilibrium points, one of which is a minimum threshold value, and the other is a high numbers equilibrium point $(\mathrm{K})$. Moreover, these authors write about cooperation as moving $\mathrm{K}$ upwards. Very similar graphs (but sometimes without the high density component) occur also in Courchamp et al. (1999a, fig. 1), Gregory \& Courchamp (2010), Kramer et al. (2009, fig. 1a), Stephens et al. (1999,

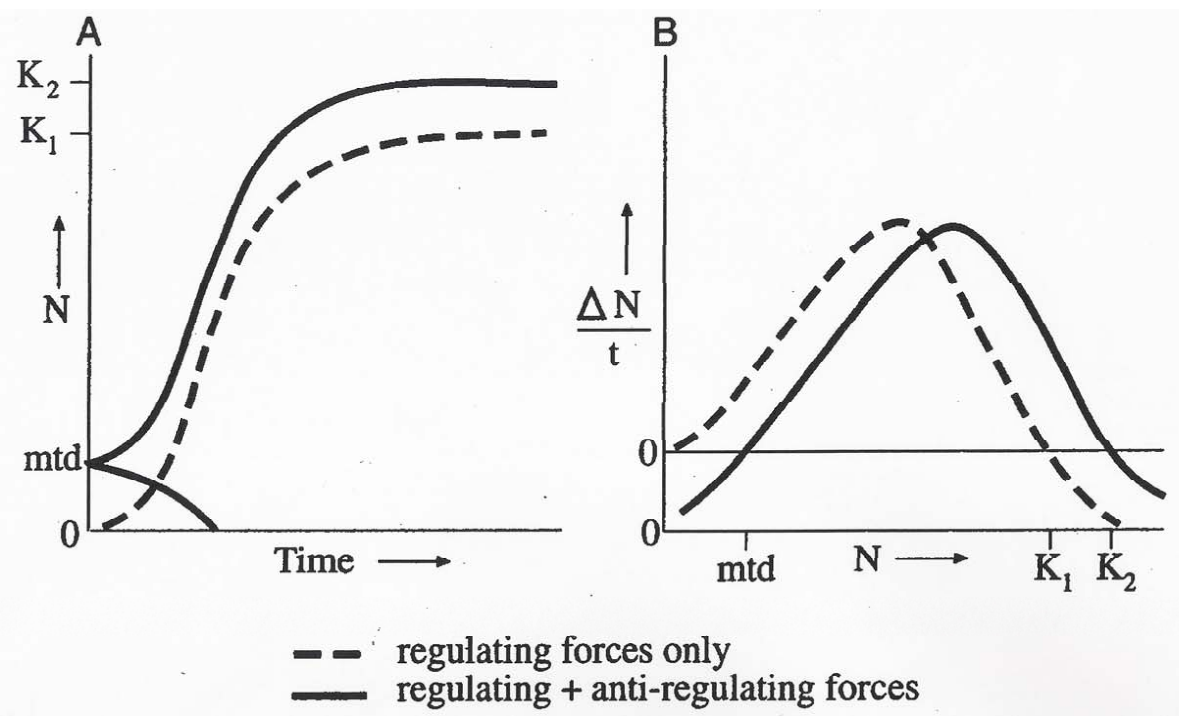

Fig. (1). Allee effects as they relate to population growth trajectories, growth rates, and population numbers in a deterministic model. Mtd = minimum threshold density; $\mathrm{K}=$ equilibrium density. A. Deterministic changes in population size (N) over time when regulating forces only are operating and when anti-regulating influences are added. B. Population growth rate as a function of population size, with and without anti-regulating forces (from Lidicker 2007, fig. 38.4). 
fig. 1d), and Stephens \& Sutherland (1999, box 2). It is therefore apparent that Allee's basic concept, at least at the low density end of the spectrum is widely acknowledged as appropriate today, albeit sometimes with various elaborations.

\section{WHAT IS THE EMPIRICAL EVIDENCE FOR ALLEE EFFECTS?}

As mentioned, this essay will not attempt to document the evidence for Allee effects as a number of recent reviews cover this aspect of the subject. Special mention is warranted for Kramer et al. (2009) which does a comprehensive review of the literature back to 1976 . However, only low density and non-experimental examples are included. Even this restricted coverage clearly shows a low level of publication to about 1991 when a rapid growth period ensues. Other important reviews include Berec et al. (2007), Courchamp et al. (1999a, 1999b, 2008), Dennis (2002), De Roos et al. (2003), Fowler \& Baker (1991), Gascoigne \& Lipcius (2004), Gregory \& Courchamp (2010), Hutchings \& Reynolds (2004), Morris (2002), Stephens \& Sutherland (1999), and Stephens et al. (1999). Some of these reviews were impressed with the scarcity of data papers, and others emphasize their abundance. If one incorporates the earlier work on high density effects and experimental studies, mostly on invertebrates and micro-organisms, there was in fact much empirical evidence for Allee effects even before the flood of publications in the last few decades. While some of the earlier research may be judged not up to modern standards technically, much remains of value, and we should not ignore the evidence it represents.

My overview of the empirical evidence for Allee effects starts with Allee's books and major papers on the subject $(1931,1932,1938,1951)$ that are filled with experimental and other evidence at both high and low densities in an impressive variety of organisms. To this we can add Darling's book on sea birds (Darling 1938). The classic text by Allee et al. (1949) contains many examples of both high and low density effects. Andrewartha \& Birch (1954), another classic, devoted 15 pages to undercrowding ("underpopulation") and gave many more examples. These authors even speculated that undercrowding may be more important than crowding in population dynamics. After this groundswell of research from leading ecologists, the idea dropped out of the mainstream for several decades. It was kept alive, however, by Eugene Odum's classic texts in ecology (Odum 1953 to 1983) and a steady trickle of empirical work. This decline in interest is reflected in the ecology texts appearing during the quarter century 1954 to 1978. In a survey of 11 such texts, 10 give no mention of Allee effects. One (Knight 1965, p. 216-218) gives a brief treatment based mostly on Allee et al. (1949). Subsequently, Begon, et al. (1986) gave us two sentences on the subject, and Yodzis (1989) several paragraphs.

A search for "Allee effect" in the BIOSIS data base (which starts in 1924), reveals that there were 10 papers published on this topic up to 1945, and this is in spite of the fact that the term "Allee effect" was not widely known or used in that period. Wynne-Edwards (1986) insists that the term was first used by Thomas (1973), but this is clearly not true. Then from 1945 to 1978 , only 4 additional papers are listed. In the decade 1979 to 1988 there were 7 more contributions, and this increased to 36 papers in 1989 to 1998. After that, there were 272 entries ending in early 2009 , for a total of 329 citations. This record cannot of course be considered more than an index to activity on the subject as it would not include relevant papers that did not include the term "Allee effect" in the title or abstract. For example, Allee and Darling effects are fully treated in Lidicker (1978), a review that is based on a symposium held in 1976. E. O. Wilson in his now classic book on Sociobiology (1975) cites 8 papers by Allee, but only one of these actually concerns Allee effects (a term not used by him), and that was a report on Mennonite communities in North America in which it had been observed that more than 50 families are needed for demographic stability. Interestingly this threshold number later declined to 20 to 25 families because of increased travel and communication among groups (Allee et al. 1949). Wilson (1975) mentions the Darling effect (and Fraser Darling effect), and in addition to the examples of predator swamping described by Darling (1938), he cites 4 additional species of birds exhibiting this behavior, and moreover adds one bird and two species of mammals to the list of those showing synchronized breeding. More examples of predator swamping are cited in Lidicker (1994, p. 336).

We can summarize research on the Allee Effect during this early period and up to the re-awakening of interest in about 1989 by noting that it was dominated by studies on birds and mammals, although amphibians, fish, and invertebrates were not entirely neglected. At least one paper on plants appeared (Jennersten 1988) in which inadequate pollination was observed in small populations. Wildlife biologists were quite interested in the failure of predator defenses in ungulates with low numbers, and vector control specialists were looking for low density negative effects to control pests (eg. Glasgow 1963). Another focus of interest was spearheaded by O. P. Pearson (1985), and involved evidence for progressively increasing predator pressure exacerbating the severe declines of arvicoline rodents exhibiting multi-annual cycles in numbers.

The upsurge of publications beginning in the 1989/1990 period was punctuated by the appearance of a comprehensive review by Dennis (1989). As mentioned, this was followed by a series of recent reviews, and I add only that while mammals and birds continue to dominate the evidence, plants, invertebrates, and micro-organisms are now much better represented. In the case of plants, evidence is reported for inadequate pollination in very small populations leading to extinctions (Groom 1998, Kunin 1993, Lamont et al. 1993, Roll et al. 1997). Other potentially important new research directions that are emerging include improved a) problem solving by individuals in large versus small groups (Liker \& Bókorny 2009), b) understanding of communitylevel functions such as indirect positive symbioses emerging from interspecific interactions (Palmer et al. 2008, Kappes \& Davis 2008), and c) coevolutionary promotion of direct positive coactions (Pennisi 2006).

Lastly, I would like to mention increasing interest in Allee effects in the marine environment. Gascoigne \& Lipcius (2004) point out that marine systems are often thought to be immune from Allee effects because it has 
generally been assumed that marine populations are immense and panmictic. Nevertheless, they conclude from their modeling study, which mainly incorporates mortality rates, that Allee effects may operate similarly in marine and terrestrial systems. Hutchings \& Reynolds (2004) summarize data on 230 populations comprising 35 species of marine fish, and find that many of the $83 \%$ of these populations that have declined have failed to respond to rescue efforts for up to 15 years. The authors suggest that Allee effects may be among the factors responsible for these failures to recover after population collapse. Particularly important from an economic and sociological perspective is the $99.9 \%$ decline in the Canadian population of the Atlantic cod (Gadus morhua) with no recovery in evidence (see also De Roos, et al. 2002). They further report that 55 species have become extinct from parts of their historic range, and three species have become globally extinct. Although explanations of these fisheries failures are complex, over-exploitation is clearly the primary cause, but anti-regulating factors may be responsible for lack of recovery or the final extinctions (see also De Roos et al. 2003, Rose \& Kulka 1999, Roughgarden \& Smith 1996). With respect to whales, Fowler \& Baker (1991) argue that, in spite of a lack of direct demographic data, whales are likely to demonstrate low density Allee effects and certainly would not be capable of increased population growth rates as numbers decline as traditional theory would predict. An early paper by Myers et al. (1995) appears to contradict these three reviews. These authors, however, were searching for evidence of multiple equilibrium states and viewed the Allee effect as involving increased difficulties in mate finding at low densities. Although they therefore examined reproduction only, three of 128 fish stocks showed statistically significant evidence for a low numbers equilibrium state. A marine pathogen example is provided by a minimum persistence threshold in the phocine distemper virus (Swinton et al. 1998).

\section{THE ALLEE EFFECT IN DEMOGRAPHY}

We now turn to the question concerning whether or not there are some fundamental properties that usefully and logically define Allee effects. So far we have seen that Allee developed the concept of mutually beneficial interactions among individuals in a population possibly leading to the emergence of a demographic pattern in which the equilibrium density $(K)$ was higher than if the beneficial interactions were absent, and in which a minimum threshold density significantly above zero might be generated. The mechanism behind these emergent demographic phenomena was the cooperative interactions among individuals living together in a group.

Before exploring how these ideas can be expressed in the language of modern population dynamics, it is necessary to clarify a few semantic issues. The size of populations is sometimes expressed in terms of numbers $(N)$ and sometimes as density (N/area). If the spatial extent of the population is a constant, the two measures are equivalent. It is not uncommon, however, for a species to be widespread, but at a low density. In such cases, the two parameters are discordant. Similarly, a very small population may live in a very restricted area and thus be at a high density. What is important for Allee effects is the interactions among individuals living near each other. Therefore, in any real situation, either numbers or density may be the most appropriate variable, and that needs to be understood. This dilemma is relieved somewhat by using the term "deme" instead of "population." A population is not consistently defined, but usually and most usefully it is formalized as more than one individual of a given kind with a boundary specified by the investigator. A deme on the other hand is understood to be a group of individuals of the same kind, but with the boundary defined by a reduced level of interactions among conspecifics. Therefore, in natural populations, the boundary of a deme is defined by the organisms of interest rather than by the investigator, and therefore will be more biologically meaningful and consistent over time compared to the more arbitrary boundaries of a "population." As a result, numbers and density are more likely to be interchangeable. Demes are also more likely than populations to reflect socially, demographically, or genetically organized entities.

I now propose that Allee effects be described and defined in terms of demographic processes in a way consistent with Odum \& Allee (1954) and many recent reviews of the concept. That is they are expressed at the population or demic level of organization, and the parameters of interest are the demic properties of growth rates, recruitment rates, loss rates, equilibrium densities, and perhaps success in establishing new demes. It is important to point out that Allee effects may or may not be manifest by these demic properties which are the products of the interactions among the particular groups of individuals that comprise the focal deme as well as interactions with numerous other biotic and abiotic factors that impinge on those individuals.

More specifically, we can summarize the demographic influences that are associated with Allee effects by noting that, as densities (or numbers) approach an upper asymptote or limit, favorable influences stimulate the population growth rate $(\mathrm{G}=\Delta \mathrm{N} / \Delta \mathrm{t})$, whereas when densities decline to low levels unfavorable influences inhibit the growth rate. A declining population may even reach a density at which the growth rate will be zero before density reaches zero. If this happens, any further declines will cause the growth rate to become negative, and this will likely be followed by demic extinction. Viewed in isolation, factors acting so as to generate Allee effects are destabilizing, tending to make populations grow toward infinity or to decline to zero. They thus act in opposition to normal density dependent regulating factors that are inherently stabilizing. In a deterministic model, actual growth rates result from a balance of these two types of antagonistic (stabilizing and destabilizing) forces.

We can usefully quantify the above scenario, by transforming the absolute growth rate $G$ to a per capita rate (sometimes called specific growth rate) by dividing $\mathrm{G}$ by $\mathrm{N}$ $(=\mathrm{g})$. Ignoring stochastic influences, per capita growth rate is determined by taking the maximum per capita growth promoting rate $(p)$ and subtracting per capita suppressing influences $(s)[g=p-s]$. Control or regulation of numbers requires influences (factors) that increase their negative influence exponentially as density increases (Fig. 2). Use of per capita rates assures that changes in these parameter values will generate exponentially changing effects on numbers. The parameter $p$ is like the traditional intrinsic rate 
of growth $\left(r_{m}\right)$ but includes net immigration, and so it is not a constant. Suppressing factors include mortality, emigration, and any negative influences on reproduction and immigration. Both $p$ and $s$ are complex parameters that represent the net per capita rates that result from multiple interacting factors (Lidicker 2002). Deterministic regulation of population numbers produces a generalized $\mathrm{S}$-shaped growth trajectory (Fig. 1), and is mainly the result of factors that increase $s$ as density increases (Fig. 2). Small changes in $p$ resulting from modification of the net immigration rate can contribute as well. For example, net immigration may increase at low densities and/or become negative with high numbers. These are the regulatory factors operating on a subject population. In contrast, factors which tend to decrease $s$ as density increases and/or increase $s$ at low densities are destabilizing, that is anti-regulating, and these are the forces that result in Allee effects at both high and low densities (Figs. 1, 2).

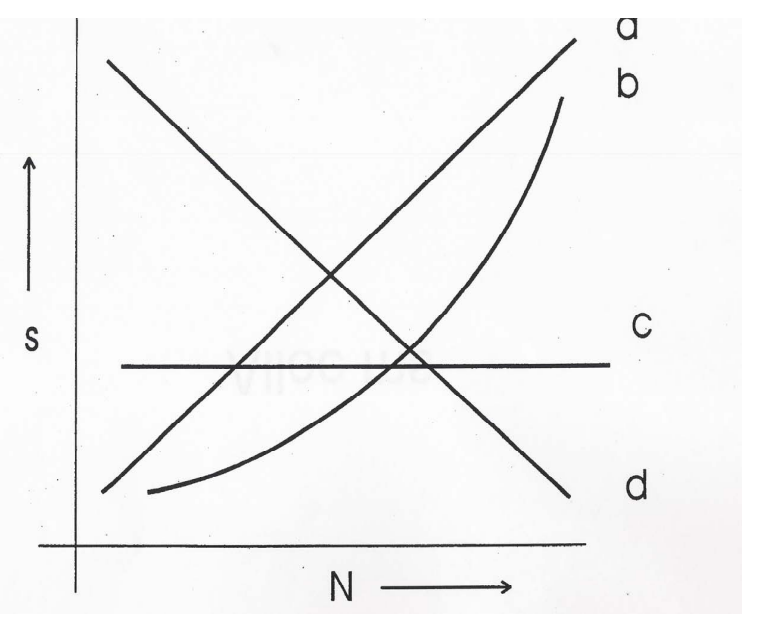

Fig. (2). Per capita growth suppression $(s)$ as a function of population abundance $(N)$ or density. a, $\mathbf{b}$ - regulating factors, $\mathbf{c}-$ non-regulating factors, $\mathbf{d}$ - anti-regulating factors (from Lidicker 2002, fig. 1).

Regulatory influences (often called density dependent), are sometimes labeled as negative, direct, or positive density dependent. The semantic dilemma is that all three of these terms plus density dependent by itself can logically be applied to anti-regulating factors as well. The intensity of both regulating and anti-regulating influences depends on density, they both can act directly or indirectly, and both have positive and negative phases depending on density. For example, with increasing density, regulation requires a positive association between density and negative forces on growth. More detailed discussion of the inherent ambiguity in these terms can be found in Lidicker (1978). This includes the seldom considered confusion caused by sometimes using density dependent to refer to the behavior of the relevant factors impinging on the subject population, and sometimes to the effect of that factor on the population. For example, in principle a population preyed upon by a predator population that stays the same size regardless of prey numbers and hence behaves in a manner independent of prey density ("density independent"), might well have an effect on the prey population that is different at various prey densities ("density dependent"). If everyone were to use "density dependence" only in the sense of "regulating" all would be well. Regulation, however, requires more than that influences on growth change in the appropriate direction with density changes. They must change exponentially in the correct direction as well. Rarely is this distinction appreciated when "density dependence" is invoked. This critical distinction is similarly compromised when antiregulating forces are named inverse density dependent. While this term clearly suggests forces that contrast with regulation, there remains the uncertainty of whether exponential changes are involved. Until there is more general acceptance of precise definitions of the density-dependence family of terms, I think it is important for authors to be clear about how they are using them. In the meantime, I prefer the regulating and anti-regulating terminology (Lidicker 1978, $1988,2002,2007)$, because it is accurately descriptive, and hence unambiguous. I will use it in the rest of this paper.

Finally, we must consider the demographic implications of this mixture of regulating and anti-regulating influences with which populations are subject. Regulating factors acting alone generate an S-shaped growth trajectory with an equilibrium density or $K$ which is stable (densities $>K$ have a negative growth and the population declines while densities $<K$ have positive growth and densities increase); see Fig. (1). If anti-regulating influences are present, $K$ may be higher or reached more quickly, but the stable equilibrium does not disappear. At low densities, regulating influences are dominated by very weak suppressing influences, and per capita growth may approach maximum possible levels. The addition of anti-regulating forces at low densities, however, can generate a second equilibrium that in this case is unstable. Densities above this equilibrium level will have positive growth rates boosting the population away from the threshold density. In contrast, densities below the threshold will continue to decline toward extinction (Fig. 1), as suppressing influences will exceed promoting forces. The downward spiral in which such populations are caught can only be reversed by the rescue effect of immigration, possibly a favorable stochastic event, or a change in the mix of anti-regulating forces. Without such rescue, the vortex to extinction proceeds regardless of what factors may have reduced population numbers in the first place.

This minimum threshold density generated by antiregulating influences is an extremely important possible outcome. It has been labeled in various ways. Examples include the Allee threshold (Angulo et al. 2007, Courchamp et al. 2008), minimal population size (Darling, 1938), minimum threshold (Courchamp et al. 1999b), minimum population threshold (Keeling \& Grenfell 1997), persistence threshold (Swinton et al. 1998), critical number (Stephens et al. 1999, Wilson 1975), critical density (Courchamp et al. 1999a, Dennis 1989), and extinction threshold (Yodis 1989). Whatever it is called, this threshold created by antiregulatory effects is a phenomenon of growing interest to conservation biologists. The term "depensation" found in the fisheries literature is not used consistently, but generally seems to be a synonym for anti-regulating effects at low densities plus the inclusion of stochastic influences, and does not necessarily imply a possible minimum threshold. 


\section{ROLE OF STOCHASTICITY}

So far, I have emphasized the deterministic role of antiregulating influences in defining the conceptual framework that generates Allee effects. However, all ecologists agree that deterministic population dynamics are buffeted by stochastic forces. Such forces impinge on populations independently of the state of those populations, although their impact will likely vary with population density. One cannot pretend to understand population processes if stochastic factors are ignored, and this is especially true at low population numbers. The question that I would now like to address is whether chance factors should be in whole or in part incorporated into our concept of the Allee effect. Regulating factors are defined deterministically, and as I have argued so are anti-regulating factors (Fig. 2). I have proposed defining Allee effects as the product of deterministic anti-regulatory influences on population demography. Should we enlarge the Allee effect concept to incorporate stochastic influences? Most recent reviewers who have considered this issue agree that stochastic influences should not be part of the Allee effect concept (Bessa-Gomes, et al. 2004, Courchamp et al. 1999b, 2008, Dennis 2002, Stephens et al. 1999), but see Lande (2002). However, most of these authors propose a single exception to this rule, and that is the stochastic variation in sex ratios that increase in variance as numbers decline. Any analysis of the Allee effect concept requires that this proposed exception be addressed.

The argument for including sex ratio stochasticity in the Allee effect concept is that 1) random changes in sex ratios at low numbers can strongly influence population viability especially in species with certain mating systems, and 2) such sex ratio fluctuations reduce the fitness of the individuals in the deme in a way analogous to anti-regulating factors, and hence should be included. There is no disagreement with the validity of the first argument, although it needs to be pointed out that other kinds of stochastic forces, such as mortality factors, can also have strong influences at low densities. Therefore strong effects are not a sufficient reason to incorporate them. The second argument is in my view a statement about the more general challenge of mate finding that may predictably be felt strongly as numbers decline. Mate finding is a well established potential component of anti-regulating influences (Bessa-Gomes et al. 2004, Gascoigne et al. 2009), and is to be anticipated in all species that have mating types (gonochorism, dioecism, multiple mating type polymorphisms, anisogamy). However, finding mates does not depend on sex ratio alone, since other factors may be influential such as the mating system, species vagility, and the spatial arrangement of individuals in their habitat (dispersion).

Other things being equal, monogamous mating patterns carry a higher variance in mate finding success than do various types of polygyny (Bessa-Gomes et al. 2004). In a deme of two (assuming a species with two mating types), mate finding success would average 0.5 with sex ratios varying from $0: 2$ to $2: 0$. In a deme of three there are six different possible sex ratios, but average mate finding success would be 0.5 if monogamy prevailed or 0.67 if polygyny were the mating system. So, it is really not the sex ratio per se that determines average mate finding success.
Moreover, its consequences have at least in part an intrinsic explanation embedded in the life history of the subject species, and hence are unlike the typical stochastic impacts that originate outside of the demic system such as unusual weather.

The second argument also introduces the prospect of individual fitness being reduced in low density populations because of high variance in sex ratios. If we assume that fitness here is meant to be genetic (Darwinian) fitness, then the argument is flawed. Variations in sex ratio generate fitness differences between the sexes, but no average fitness variation within each sex. This is because the average genetic contribution of a male to the next generation is $1 / m \mathrm{x}$ $1 / 2$ where $m$ is the number of reproductive males in the deme; similarly the mean female contribution is $1 / f \times 1 / 2$. Moreover, individuals from small populations contribute proportionately more genes to future generations than do individuals from large demes. So, individual genetic fitness is not based on stochastic variation in sex ratios, and does not fit as an anti-regulating factor. Dennis (2002) also makes the important point that stochastic factors do not contribute to the generation of minimum threshold densities ("lower critical thresholds") and in fact differ very little above and below such thresholds.

If the "fitness" in argument number 2 has to do with general well-being (health, low stress levels, good survival rates) and not genetics, "fitness" of this sort is unlikely to be affected by chance sex ratio variations. Moreover, rather than being reduced, individual well-being may be quite high at low densities because, depending on the reasons for the low numbers, there might well be an abundance of resources and minimal intra-specific competition. Average well-being, moreover, will not likely be sex specific. Therefore this interpretation also does not support the inclusion of chance sex ratio variations in Allee effects.

I conclude that there is not a compelling reason to include sex ratio variance in the Allee effect concept. Less confusion will, I submit, result if the Allee effect is defined as resulting only from deterministic anti-regulating influences (Fig. 2). This conclusion does not of course diminish the importance of considering stochastic forces at all densities in any comprehensive treatment of population dynamics.

\section{SOME NEW TERMINOLOGY AND THE ALLEE EFFECT}

In recent years, much new terminology has been proposed to improve understanding and the usefulness of the Allee effect concept. In this section, I will briefly summarize these developments. Depensation has already been introduced as an older term used mainly by marine ecologists to express low density negative effects on population dynamics in general terms. Improved clarity would probably result if this term was explicitly connected to Allee effects (e.g. Gascoigne \& Lipcius 2004).

Of greater significance is the introduction of a suite of terms that subdivide anti-regulatory forces into various components. These new terms serve to emphasize that these forces can be of various strengths, be direct or indirect in 
their effects on individuals and on various demic attributes, or can be the result of various specific kinds of influences, for example predation. This effort is motivated by the desire to determine more specifically the mechanistic nature of influences leading to anti-regulating forces and hence Allee effects. Berec et al. (2007) provide a useful summary of this suite of new terms. They define 13 different kinds of Allee effects, all of which can interact with one another. These include, for example "strong Allee effects" that generate Allee thresholds and "weak Allee effects" that do not produce such thresholds. Another often used dichotomy is that of "component Allee effects" defined as a positive relationship between any measurable component of individual fitness and the population properties of size or density, and "demographic Allee effects" defined as a positive relationship between total individual fitness (defined as per capita population growth rate) and population size or density (Berec et al. 2007).

One aspect of this proliferation of terminology is the proposition to frame Allee effects in terms of average individual (Darwinian) fitness (Berec et al. 2007, Bessa-Gomes et al. 2004, Courchamp et al. 1999b, 2008, Gascoigne \& Lipcius 2004, Stephens \& Sutherland 1999, Stephens et al. 1999). It is certainly appropriate that research be directed toward improving our understanding of the fitness consequences of density changes that we observe. Moreover, it is likely that study of the various components of fitness will add insights into our understanding of the mechanisms of population behavior. It seems appropriate to consider, however, if this trend toward subdividing Allee effects into components and including the concept of individual fitness to define these components has been helpful.

To begin this inquiry, we need to ask what we expect from a good definition. In my view, the most useful definitions in science are phenomenological, that is, they describe some aspect of the universe that requires explanation. If such a phenomenon is tied by definition to some mechanistic explanation too early in our pursuit of understanding, research is narrowed by that restriction to a particular mechanism, and moreover will likely leave unstudied the possibility of some different mechanism being involved. For example "Evolution is genetic change over time in populations" invites a search for mechanisms, whereas "Evolution is genetic change in populations through natural selection" narrows the arena of research on evolution. I would therefore like to recommend a phenomenological definition of Allee effects. The various particular mechanistic explanations can then be presented as such, and therefore contribute to a growing empirical basis of understanding without changing the core definition. If it should turn out that a phenomenon of interest is always caused by one particular mechanism, then it is time to add that mechanism to the definition.

In order to explore whether or not there are in fact potential concerns resulting from this proliferation of new definitions, we need to review a sample of recent literature on this issue. Courchamp et al. (2008, p vi) say that the Allee effect "is simply a causal positive relationship between the number of individuals in a population and their fitness." Berec et al. (2007) list 13 kinds of Allee effect, but provide no overall concept. Stephens et al. (1999: p.186) define the
Allee effect as "a positive relationship between any component of individual fitness and either numbers or density of conspecifics," a corollary of which is the claim that undercrowding is principally a population-level phenomenon which may or may not arise from changes in individual fitness and thus need not be directly analogous to the Allee effect. Similarly, Gascoigne \& Lipcius (2004) say that "An Allee effect occurs when some component of fitness deteriorates as population density or size decreases toward zero." Finally, Stokes \& Boersma (2000, p. 2879) claim that the Allee effect results from declining individual fitness as density increases. These few examples illustrate how fitness criteria are being widely introduced, not just to explain Allee effects, but to define them. This trend concerns me because 1) it ties the Allee effect mechanistically to average individual fitness that changes in specified ways with density; 2) it will a) require an investigator to measure average individual fitness over a range of densities, which is usually very difficult to do, and for some definitions multiple components of fitness must be measured as well, or b) entice the investigator into using a surrogate for fitness such as a single component of fitness or well-being that can be more easily determined, or even per capita population growth rate or population density (Berec et al. 2007, Lande 2002); and 3) even after successfully completing this difficult protocol, will the new insights obtained improve our understanding of Allee effects, given the variety of definitions to choose from, and will they translate into effective conservation applications?

To explore these concerns further, we need first to point out that individual fitness is an a posteriori measure of an individual's success (preferably life time) in passing on its genotype to subsequent generations, and is scaled relative to other individuals of reproductive age in its deme. The challenge is that if individual fitness is to be a key component of defining Allee effects, how can we measure it, and how can we use this index to learn about Allee effects. There is no doubt that measuring it is difficult, and that assessing the role of anti-regulating factors in these measurements adds complexity to this effort. Moreover, these challenges are only exacerbated by those authors who claim that any of the multiple components of individual fitness, can generate an Allee effect with or without any demographic consequences (Gascoigne \& Lipcius 2004, Stephens et al. 1999), and hence are operationally invisible. Appropriately, Gascoigne \& Lipcius (2004, p 57) offer the warning that "... clear demonstrations of component Allee effects are likely to require large-scale manipulative experiments, and will therefore be limited to a few taxa."

Can we use surrogates to measure individual fitness? One possibility is to use components of fitness which are much easier to measure. These, however, can be influenced by any environmental factor that affects an individual's ability to successfully pass on its genotype, and so there are a great many possibilities to investigate. Success in finding suitable candidate components is complicated by this great number and by the probability that different individual's will use different strategies or combinations to achieve success. In spite of these precautions, there are two demographic parameters that are widely recommended as surrogates for fitness, namely, population density and per capita growth rates. But, do these demographic parameters carry good 
information about individual fitness? Investigations into the relations between individual fitness and density change (both in level and direction) represent an important area of research that has deep roots. Thus we know that individual fitness can vary considerably among individuals at any given time, and does not scale to density in any consistent way. Short-term measures of individual fitness will be zero to low when population numbers are declining, both at low densities (when they are below a minimum threshold density) or at high densities (when above K). Densities in between will support various fitness levels, often high at relatively low densities and progressively lower as densities increase. Moreover, there may be genetic polymorphisms influencing differential success among individuals at high or low densities. These complexities lead to the conclusion that density is not a good surrogate for individual fitness.

Individual fitness also does not scale consistently with per capita population growth rates $(g)$ either with or without significant anti-regulating influences. The fit, however, may be somewhat better than with density. When $g$ is negative at either high or low densities, short-term fitness values will be also be low. Positive $g$ values imply that reproduction and survival are favorable and individual fitnesses will be higher. It is not clear; however, whether over the range of positive growth rates, fitness will correlate positively and consistently with growth rates. It seems likely that individual fitnesses will be higher early in population growth when densities are relatively low than at higher densities as growth rates slow. Anti-regulating forces at high densities will slow that decline but by how much? At lower densities, they will inhibit the usual increase in $g$, but by how much? Moreover, per capita growth rates are complexly related to densities (Sibly et al. 2005), and so do not reliably incorporate density information that might be thought to improve the fitness information content of $g$ values. Thus, per capita growth rates are unreliable surrogates for average individual fitness, and should be avoided.

In spite of these considerations, bringing individual fitness into the study of anti-regulating factors is a promising direction, but needs to be directed to elucidating the mechanisms of anti-regulation in specific cases. In pursuing this objective, we must bear in mind that anti-regulatory influences are likely to be an integration of multiple forces, as emphasized by Berec et al. (2007), and that this also characterizes regulating influences. These integrated regulating and integrated anti-regulating forces then combine to generate the main deterministic aspects of population dynamics. The actual population behavior is further confounded by the impingement of forces unrelated to density (density independent) and stochastic events. Given this anticipated complexity, it will be very difficult to determine the extent to which any particular anti-regulating component of this complex and dynamic demographic nexus contributes to overall mean individual fitness. For example, improved predator defense at high numbers might well lead to improved survival rates and hence a positive demographic effect, as well as a presumed impact on mean individual fitness. However, there may be no corresponding increase in fitness because of factor interactions such as in this case a possible increase in competition for food or inadequate supply of nesting sites. I suggest that instead of including individual fitness in the core Allee effect concept, we need to establish a solid phenomenological definition for Allee effects, and then use this foundation to build new layers and new dimensions of mechanistic understanding, which of course might include measures of individual fitness components.

\section{DISCUSSION AND CONCLUSIONS}

This review has three objectives: 1) to summarize the history of the Allee effects concept back to the latter part of the $19^{\text {th }}$ century; 2) to search for a core concept that defines Allee effects and that then can be used as a substrate on which to build new mechanistic insights into our understanding of population dynamics, while also considering the potential role of recently proposed new terminology in this process; and 3) to emphasize the growing appreciation of the nearly ubiquitous role that mutually beneficial interactions or coactions have in demography and by extension in community dynamics, and to offer some thoughts for possible future research directions.

The history of the Allee effect concept has been shown to be closely allied with the history of recognizing the importance of mutually positive interactions among individuals in populations, and has its origins in antiquity. In the $19^{\text {th }}$ and earliest 20th centuries several classic writers can be viewed as foundational (Darwin 1859, 1872, Espinas 1877, Kropotkin 1902, Wheeler 1928). Starting in the second decade of the $20^{\text {th }}$ century, W. C. Allee and his colleagues established the concept empirically, first as an enhancing effect on high density populations and then as a negative influence at very low densities. These two aspects of demography can be joined in the principle of anti-regulating effects (Lidicker 1978, 1988, 2002, 2007), sometimes known as inverse density dependence. The pivotal role of the "Chicago school of ecology" in this history has been described by Mitman (1992). It was a success story, abetted by others such as F. F. Darling, H. G. Andrewartha, and L. C. Birch. Collectively they established the widespread nature of these phenomena in animals and microorganisms, with extensive experimental and observational investigations. The experimental data in particular emphasized how the effects of inter-individual cooperation, or lack thereof, could easily be extrapolated into population-level demographic parameters

There followed almost four decades in which cooperative interactions were considered to be destabilizing (which they are) and therefore rare and inconsequential (which they are not), and so the dominant paradigm became an overwhelming emphasis on negative interactions, especially competition, both intra- and inter-specific, in the organization of populations and communities respectively. Data on cooperative interactions continued to accumulate, however, and by the end of the 1980's Allee effects once again became a respected part of population (and community) ecology. In the last two decades, an exponential increase in interest, research findings, and understanding have ensued. Although cooperative interactions are often associated with social behavior, De Roos et al. (2003) point out that Allee effects can occur in the absence of such behavior, namely through various life history traits that they exclude from the concept of cooperation. However, I use the term to mean any 
mutually beneficial $(++)$ interactions (Lidicker 1979). Therefore a group of plants growing near each other and thereby enhancing their pollination efficiency is cooperation even though not social behavior.

Building on this history and the large body of recent new information, I explore the question of an appropriate definition for Allee effects, starting with the bias that in science definitions should preferentially be phenomenological, that is descriptive and not explanatory. This allows maximum license for investigators to search for mechanistic understanding of the phenomenon of interest, and moreover allows for multiple causes. Putting explanations into definitions prematurely, limits the search for alternative or multiple explanations. Therefore, I propose that Allee effects be simply defined as the demographic consequences of antiregulating forces. If there are no demographic effects of such influences, there can be no Allee effects, even though weak anti-regulatory forces may still be present and operating. It is understood that such forces may be weak or strong, direct or indirect, a result of the combination of multiple components acting synergistically, additively, or antagonistically, and have any number of mechanistic causes. My proposed definition puts into modern terminology what I believe W. C. Allee came eventually to espouse.

The recent tendency to develop a plethora of new terminology, both to define Allee effects and to describe various components of anti-regulation, can be useful in moving us toward better explanatory understanding of these phenomena. Some caution needs to be mentioned, however, relating to the now popular incorporation of individual fitness into the Allee effect concept. Fitness is notoriously difficult to measure, and is only complexly and idiosyncratically related to density or numbers. Lewontin (1974), for example, claims that the difficulties of estimating fitnesses are "virtually insuperable." It is much easier to measure individual fitness components, although they have the disadvantage that they are an unknown, possibly tiny, part of total individual fitness, and are only potential or predictive contributors to fitness. The concept of Component Allee effects, popular in much of the recent literature (Berec et al. 2007), captures this potential utility quite well. Such effects are defined as any measurable component of individual fitness that is positively correlated with density or numbers. In fact this concept is very close to a definition of antiregulating factors (Fig. 2d). Component Allee effects promote individual fitness as a function of population density or numbers; anti-regulating forces promote declining per capita suppressing effects as density or numbers increase. The differences are subtle but important: 1) It is all too easy to assume that by involving individual fitness components here, that one is actually measuring mean individual fitnesses, which is not the case; and 2) The definition of Component Allee effects does not distinguish between arithmetic changes of what is being measured and exponential changes (per capita). Only the latter will result in changes in the impact of the focal factor in the prescribed direction. Anti-regulating factors do not carry these disadvantages nor are they encumbered with the logistic problems related to measuring fitness and/or its components. Similarly, Demographic Allee effects are defined as a positive relationship between per capita population growth rate (assumed to equal total individual fitness) and population density or size (Berec et al. 2007). In this case the parameter measured $(g)$ is a per capita rate so this is an advantage. However, as pointed out, $g$ is not a reliable correlate of individual fitness, and most importantly it is complexly related to density and would not be positively correlated except at low densities (Sibly et al. 2005) with or without anti-regulating influences being present. I conclude that while connecting fitness attributes to population dynamics is an important direction for investigation, it should be based on analyses that seek to identify and measure the many interacting factors, including antiregulating forces and their possible manifestations in Allee effects that contribute to those dynamics.

Cooperative $(++)$ interactions are becoming increasingly appreciated as ubiquitous at all levels of biological organization. Gregor et al. (2010) and Teilrooij et al. (2010) are recent examples of this trend at the protistan and molecular levels respectively. I therefore predict that anti-regulation and its corollary Allee effects will increase still more in importance because they will be potentially relevant to any consideration of demographic phenomena.

Future research on Allee effects must continue to unravel the multiple components of anti-regulating forces and to pursue our understanding of how they interact with regulating and stochastic influences. It is particularly important that we improve our understanding of small population dynamics, both from the perspective of single populations and in metapopulation arrays. Fryxell et al. (2010) illustrate how, even for common species, management strategies can lead to population collapses if they fail to prevent even occasional low number episodes. We also need to investigate the kinds of life histories and perhaps the sorts of environments that are associated with stronger antiregulation. Success in this direction will allow us to be more predictive with regard to conservation biology and wildlife management. It is well known that complex social behavior is associated with anti-regulation including minimum threshold densities (Allee thresholds), but what about a) passive cooperation such as aspects of pollination biology, b) relatively unstudied taxa such as micro-organism aggregations, and c) species that typically live at low densities and may routinely experience difficulties finding mates? Another intriguing area of research involves species with sizestructured life history traits in which adults prey on younger stages (De Roos \& Persson 2002, De Roos et al. 2003).

Particularly exciting is to move the analysis of mutualistic (cooperative, ++ ) interactions to the community level. There are at least two aspects to this prospect. The first is to search for demographic processes analogous to antiregulating ones resulting from interspecific beneficial interactions (coactions). Certainly, there is increasing awareness of the importance of beneficial interactions in the structuring of communities, and an analysis of the demographic implications of these coactions is in its infancy. The second arena is in the study of multiple stable states in community dynamics (Suding \& Hobbs 2009). It seems likely that minimum threshold densities, especially of dominant or keystone species can play transformative roles in degrading communities or in those changing in response to rapid climate changes. Possible shifts to alternate steady states that are difficult to reverse are fundamental issues in 
restoration ecology (Hobbs and Suding 2008, Schröder et al. 2005, Suding et al. 2004).

\section{REFERENCES}

Allee, WC (1931) Animal Aggregations, a Study in General Sociology, Univ. Chicago Press, Chicago.

Allee, WC (1932) Animal Life and Social Growth, Williams \& Wilkins Co., Baltimore.

Allee, WC (1938) The Social Life of Animals, Norton, New York.

Allee, WC (1951) Cooperation among Animals, with Human Implications, Henry Schuman, New York.

Allee, WC \& Bowen, E (1932) Studies in animal aggregations: mass protection against colloidal silver among goldfishes. Journal of Experimental Zoology, 61, 185-207.

Allee, WC, Emerson, AE, Park, O, Park, T \& Schmidt, KP (1949) Principles of Animal Ecology, W. B. Saunders, Philadelphia.

Andrewartha, HG \& Birch, LC (1954) The Distribution and Abundance of Animals, Univ. Chicago Press, Chicago.

Angulo, E, Roemer, GW, Berec, L, Gascoignes, J, \& Courchamp, F (2007) Double Allee effects and extinction of the Island Fox. Conservation Biology, 21, 1082-91.

Begon, M, Harper, JL \& Townsend, CR (1986) Ecology: Individuals, Populations and Communities, Blackwell Sci. Pub., Oxford.

Berec, L, Angulo, E \& Courchamp, F (2007) Multiple Allee effects and population management. Trends in Ecology and Evolution 22: 18591.

Bessa-Gomes, C, Legendre, S \& Clobert, J (2004) Allee effects, mating systems and the extinction risk of populations with two sexes. Ecology Letters, 7, 802-12.

Bourcher, DH (Ed) (1985) The Biology of Mutualism, Oxford Univ. Press, New York.

Chabrzyk, G \& Coulson, JC (1976) Survival and recruitment in the Herring Gull Larus argentatus. Journal of Animal Ecology, 45, 187-203.

Courchamp, F, Clutton-Brock, T \& Grenfell, B (1999a) Inverse density dependence and the Allee Effect. Trends in Ecology and Evolution, $14,405-10$.

Courchamp, F, Grenfell, B \& Clutton-Brock, T (1999b) Population dynamics of obligate cooperators. Proceedings of the Royal Society of London, Ser. B, 266, 557-63.

Courchamp, F, Berec, L \& Gascoigne, J (2008) Allee Effects in Ecology and Conservation, Oxford Univ. Press, New York.

Darling, FF (1938) Bird Flocks and Breeding Cycle, a Contribution to the Study of Avian Sociality, Cambridge Univ. Press, Cambridge.

Darwin, CR (1859) On the Origin of Species by Means of Natural Selection, or the Preservation of Favoured Races in the Struggle for Life, $1^{\text {st }}$ ed. John Murray, London.

Darwin, CR (1872) The Origin of Species by means of Natural Selection, $6^{\text {th }}$ ed. John Murray, London.

Dennis, B (1989) Allee-effects: population growth, critical density, and the chance of extinction. Nature Research Modeling, 3, 481-538.

Dennis, B (2002) Allee effect in stochastic populations. Oikos, 96: 389-401.

De Roos, AM \& Persson, L (2002) Size-dependent life-history traits promote catastrophic collapses of top predators. Proceedings of the National Academy of Sciences, 99: 12907-12.

De Roos, AM, Persson, L \& Thieme, HR (2003) Emergent Allee effects in top predators feeding on structured prey populations. Proceedings of the Royal Society of London B, 270, 611-8.

Dugatkin, LA (1997) Cooperation among Animals, an Evolutionary Perspective, Oxford Univ. Press, Oxford.

Espinas, AV (1877) Des Sociétés Animales, Baillières, Paris.

Fowler, CW \& Baker, JD (1991) A review of animal population dynamics at extremely reduced population levels. Reports of the International Whaling Commission, 41, 545-54.

Fryxell, JM, Packer, C, McCann, K, Solberg, EJ, \& Saether, B-E (2010) Resource management cycles and the sustainability of harvested wildlife populations. Science, 328, 903-6.

Gascoigne, J, Berec, L, Gregory, S \& Courchamp, F (2009) Dangerously few liaisons: a review of mate-finding Allee effects. Population Ecology 51, 355-72.

Gascoigne, J \& Lipcius, RN (2004) Allee effects in marine systems. Marine Ecology Progress Series, 269, 49-59.

Glasgow, JP (1963) The Distribution and Abundance of the Tsetse, MacMillan Co., New York.
Gould, SJ (1988) Kropotkin was no crackpot. Natural History, 7, 12-21.

Gregor, T, Fujimoto, K, Masaki, N, \& Sawai, S (2010). The onset of collective behavior in social amoebae. Science, 328, 1021-25.

Gregory, SD \& Courchamp, F (2010). Safety in numbers: extinction arising from predator-driven Allee effects. Journal of Animal Ecology 79, 511-14.

Groom, MJ (1998) Allee Effects limit population viability of an annual plant (Clarkia concinna). American Naturalist, 151, 487-96.

Hobbs, RJ \& Suding, KN (2008) New Models for Ecosystem Dynamics and Restoration, Island Press, Washington, DC.

Howard, HE (1920) Territory in Bird Life, Murray, London.

Hutchings, JA \& Reynolds, JD (2004) Marine fish population collapses: consequences for recovery and extinction risk. BioScience, 54, 297 309.

Jennersten, O (1988) Pollination in Dianthus deltoides (Caryophyllaceae): effects of habitat fragmentation on visitation and seed set. Conservation Biology, 2, 359-66.

Kappes, JJ \& Davis, JM (2008) Evidence of positive indirect effects within a community of cavity-nesting vertebrates. Condor, 110, 441-49.

Keddy, P (1990) Is mutualism really irrelevant to ecology? Bulletin Ecological Society of America, 71, 101-2.

Keeling, MJ \& Grenfell, BT (1997) Disease extinction and community size: modelling the persistence of measles. Science, 275, 65-7.

Knight, CB (1965) Basic Concepts of Ecology, Macmillan Co., New York.

Kozo-Polyansky, BM, Fet, V \& Margulis, L (2010) Symbiogenesis, Harvard Univ. Press, Cambridge.

Kramer, AM, Dennis, B, Liebold, AM \& Drake, JM (2009) The evidence for Allee effects. Population Ecology 51, 341-54

Kramer, AM \& Drake, JM (2010) Experimental demonstration of population extinction due to a predator-driven Allee effect. Journal of Animal Ecology, 79, 633-9.

Kropotkin, PA (1902) Mutual Aid, a Factor of Evolution. Knopf Pub., New York

Kunin, WE (1993) Sex and the single mustard: population density and pollinator behavior effects on seed set. Ecology, 74, 2145-60.

Lande, R (2002) Incorporating stochasticity in population viability analysis. In: Beissinger, SR \& McCullough, DR (Eds) Population Viability Analysis, Chicago, Univ. Chicago Press 18-40.

Lewontin, RC (1974) The Genetic Basis of Evolutionary Change. Columbia Univ. Press, New York.

Lidicker, WZ, Jr (1978) Regulation of numbers in small mammal populations - historical reflections and a synthesis. In: Snyder, DP (Ed) Populations of Small Mammals under Natural Conditions, Special Pub. no. 5, Pymatuning Lab. Ecology 122-41.

Lidicker, WZ, Jr (1988) Solving the enigma of microtine "cycles." Journal of Mammalogy, 69, 225-35.

Lidicker, WZ, Jr (1994) Population ecology. In: Birney, EC \& Choate, JR (Eds) 75 Years of Mammalogy - 1919-1994, Special Pub. no 11, Amer. Soc. Mammalogists 323-47.

Lidicker, WZ, Jr (2002) From dispersal to landscapes: progress in our understanding of population dynamics. Acta Theriologica, 47 (Suppl. 1), 23-37.

Lidicker, WZ, Jr (2007) Issues in rodent conservation. In: Wolff, JO \& Sherman, PW (Eds) Rodent Societies: an ecological and evolutionary perspective. Univ. of Chicago Press, Chicago 453-62.

Liker, A \& Bókony, V (2009) Larger groups are more successful in innovative problem solving in house sparrows. Proceedings of the National Academy of Sciences USA, 106, 7893-8.

Mitman, G (1992) The State of Nature: Ecology, Community, and American Social Thought, 1900-1950. Univ. Chicago Press, Chicago.

Morris, DW (2002) Measuring the Allee Effect: positive density dependence in small mammals. Ecology, 83, 14-20.

Myers, RA, Barrowman, NJ, Hutchings, JA \& Rosenberg, AA (1995) Population dynamics of fish stocks at low population levels. Science, 269, 1106-8.

Odum, EP (1953) Fundamentals of Ecology, $1^{\text {st }}$ ed. WB Saunders Co, Philadelphia.

Odum, EP (1983) Basic Ecology. Saunders College Pub., Philadelphia.

Odum, HT \& Allee, WC (1954) A note on the stable point of populations showing both intraspecific cooperation and disoperation. Ecology 35, 95-7.

Palmer, TM, Stanton, ML, Young, TP, Goheen, JR, Pringle, RM, \& Karban, $\mathrm{R}$ (2008) Breakdown of an ant-plant mutualism follows the loss of large herbivores from an African savanna. Science, 319, 192-5. 
Pearson, OP (1985) Predation. In: Tamarin, RH (Ed) Biology of New World Microtus. Special Publication no. 8, Amer. Soc. Mammalogists 535-66.

Pennisi, E (2006) Plant wannabes. Science, 313, 1229.

Roll, J, Mitchell, RJ, Cabin, RJ \& Marshall, DL (1997) Reproductive success increases with local density of conspecifics in a desert mustard (Lesquerella fendleri). Conservation Biology, 11, 738-46.

Rose, G \& Kulka, D (1999) Hyperaggregation of fish and fisheries: how catch-per-unit-effort increased as the northern cod (Gadus morhua) declined. Canadian Journal of Fisheries and Aquatic Sciences, 56, 118-27.

Roughgarden, J \& Smith, F (1996) Why fisheries collapse and what to do about it. Proceedings of the National Academy of Sciences, USA, 93, 5078-83.

Schröder, A, Persson, L \& de Roos, AM (2005) Direct experimental evidence for alternative stable states: a review. Oikos, 110, 3-19.

Sibly, RM, Barker, D, Denham, C., Hone, J. \& Pagel, M (2005) On the regulation of populations of mammals, birds, fish, and insects. Science 309, 607-10.

Stephens, PA \& Sutherland, WJ (1999) Consequences of the Allee effect for behaviour, ecology and conservation. Trends in Ecology and Evolution, 14, 401-5.

Stephens, PA, Sutherland, WJ \& Freckleton, RP (1999) What is the Allee Effect? Oikos, 87, 185-90.

Stokes, DL \& Boersma, PD (2000) Nesting density and reproductive success in a colonial seabird, the Magellanic Penguin. Ecology, 81, 2878-91.
Suding, KN, Gross, KL \& Houseman, GR (2004) Alternative states and positive feedbacks in restoration. Trends in Ecology and Evolution $19,46-53$.

Suding, KN \& Hobbs, RJ (2009) Threshold models in restoration and conservation: a developing framework. Trends in Ecology and Evolution, 24, 271-9.

Swinton, J, Harwood, J, Grenfell, BT, \& Gilligan, CA (1998) Persistence thresholds for phocine distemper virus infection in harbour seal Phoca vitulina metapopulations. Journal of Animal Ecology, 67, 54-68.

Thomas, JD (1973) Schistosomiasis and the control of molluscan hosts of human schistosomes with particular reference to possible selfregulating mechanisms. Advances in Parasitology, 11, 307-94.

Tielrooij, KJ, Garcia-Araez, N \& Bakker, HJ (2010) Cooperativity in ion hydration. Science, 328, 1006-9.

Wheeler, WM (1928) The Social Insects, their Origin and Evolution. Harcourt, Brace, New York.

White, JF \& Torres, MS, Eds (2009) Defensive Mutualism in Microbial Symbiosis, CRC Press, Boca Raton, FL.

Wilson, EO (1975) Sociobiology, Harvard Univ. Press, Cambridge, MA.

Wynne-Edwards, VC (1962) Animal Dispersion in Relation to Social Behaviour, Hafner Pub., New York.

Wynne-Edwards, VC (1986) Evolution through Group Selection, Blackwell Sci. Pub., Boston.

Yodzis, P (1989). Introduction to Theoretical Ecology, Harper \& Row Pub., New York.

Received: May 06, 2010

Revised: June 04, 2010

Accepted: June 09, 2010

(C) William Z. Lidicker, Jr.; Licensee Bentham Open.

This is an open access article licensed under the terms of the Creative Commons Attribution Non-Commercial License (http://creativecommons.org/licenses/by$\mathrm{nc} / 3.0 /$ ), which permits unrestricted, non-commercial use, distribution \& reproduction in any medium, provided the work is properly cited. 